\title{
Life Span Prediction of Façade Paint Coatings in Public Residential Buildings in Transitional Climatic Zone of Nigeria
}

\author{
Aluko, Olaniyi Olanipekun \\ Department of Architecture, Federal University of Technology, P. O. Box 704, Akure. Ondo State, Nigeria
}

\begin{abstract}
The lifespan of building components plays an essential role in maintenance planning and any other sustainability evaluation including an assessment of overall building performance. The use of paint as a coating on the exterior wall of both private and public buildings in Nigeria, however, remains wide and acceptable. The facades which are susceptible to deterioration ultimately affect the outlook of the buildings and the vistas of the city. The state of the painted facades of 84 buildings in Mandate 3 Estate in Ilorin which falls under the transitional climatic zone for Architectural design in Nigeria was determined through survey data generated through a structured questionnaire. The most relevant factors affecting the life span of paint and their effect on durability is studied, the relationship between the sub-factors and their influence on lifespan is assessed using multiple regressions. The model which enabled degradation patterns to be identified yielded an average (reference) service life of paint coatings of 2 years and maximum reference life of 3 years. An analysis was then performed that suggested maintenance strategies at an interval of 3 years and terminates at a period of 15 years. The suggested estimation based on a simple method that balances cost and speed, enabling its practical application to any structure that can be used by all the stakeholders in the building industry. The output from the study has confirmed that maintenance strategy built on service-life prediction data can be more efficient and reliable.
\end{abstract}

Keywords: Degradation, façade, service life, paint, maintenance.

DOI: $10.7176 /$ CER/13-2-03

Publication date: April $30^{\text {th }} 2021$

\subsection{Introduction}

The assessment of the lifespan of building components is a challenging task because data about lifespan are needed for proper maintenance planning and methods for adapting available data to the specific conditions are also required. The performance of building materials used for exterior finish cannot be ascertained precisely through simulation or laboratory experiments. It requires that the materials are applied on substrates and placed under the natural environmental condition to experience the actual changes possible over some time. The best alternative is to assess the changes through users who have lived with the changes over a long period. A good number of such users may not even take notice of the situation until questions are posed to them. The survey method that gathers information or data from such people is a suitable alternative (Morcillo, 1999., de la Fuente., 2006., Yang Wang and JU, 2012).

In the survey research, the degradation of external claddings is consequently studied and based only on visual inspection and data on degradation in real in-service conditions. This method is an alternative to the lab tests that some authors believe represent a simplification of reality and whose results do not have a clear correspondence with the complexity of the phenomena associated with natural degradation under real in-use conditions (Kus et al. 2004; Daniotti and Paolini 2005), as long as these conditions are known, the mechanisms of deterioration are understood and the causes of deterioration are identified (Norvaišiene et al. 2003). Also, durability data obtained through accelerated ageing laboratory tests which follows an analytical methodology, in which the full complexity of natural ageing phenomena is subdivided into degradation agents are generally complex, time and resourceconsuming and provide results that are not easily transposed to real-life in-use situations.

The challenge of housing delivery as discovered in form of environmental and the vista of building conditions in the study area reveals a pathetic picture of neglect, decay and deterioration. To be able to make any meaningful maintenance strategy, the service life of the building materials and components ought to be developed alongside when the degradation of such an element would reach the acceptable degradation limit. The most relevant factors affecting the life span of paint and their effect on durability is studied, the relationship between the sub-factors and their influence on lifespan is assessed using multiple regressions, hence, the values for the sub-factors are determined. Many studies have examined service life prediction based on deterministic, probabilistic and engineering methods. All the methodologies and standards including the statistical applications were done in a temperate environment different from the tropical environment of Nigeria. Therefore, the non-existent model for the quantification of service life prediction of external paint finish and the lack of maintenance guide for the stakeholders in the building industry in Nigeria is the reason why this study is relevant.

\subsection{Literature Review}

External cladding is the first and outermost layer that separates the inner space from environmental agents and is 
therefore particularly prone to failures and defects, with direct consequences for the quality of urban space, user comfort, and repair and maintenance costs

Therefore, the envelope of the building is a key element because it strongly influences its comfort, safety and aesthetics. Because building envelope is in close contact with the environment, it is constantly affected by the weather and atmospheric pollution, which can speed up the degradation rate, with likely serious implications for safety and user comfort. One of its elements, the external cladding, directly influences the thermal and environmental performance of the building envelope because of its share in the envelope's initial embodied energy and life cycle cost (Silvestre, Silva and de Brito, 2012).

The use of a material that requires frequent maintenance on the external surface due to climatic changes will not be sustainable, therefore, consideration must also be given to sustainable and durable materials which have become a global issue (Singhaputtangkul, Low and Teo, 2011). Building maintenance management can be seen as a highly complex and intricate sphere of operations, involving the interaction between technical, fiscal, legal and social determinants which govern the use of buildings (Lee and Wordsworld, 2001). Since maintenance is a diffuse operation, taking place incrementally through time, in many locations and by different organizations, the scale and importance of building maintenance work is frequently undervalued in comparison with a higher profile and more visible new construction. The poor design of construction details, a bad choice of the façade materials, its inadequate application, and non-existent maintenance are the core of current problems in building façades. Building maintenance costs have increased significantly over the years primarily due to the absence of proper maintenance management approaches in buildings. Several factors such as building characteristics, human aspects, ways of implementing maintenance and government policies can be seen to be responsible for this increase in maintenance costs (El-Haram and Horner, 2002)

Estimates of the life expectancy of building components result in different outputs depending on what is required of them. In theory, many of the components of buildings are capable of lasting a very long time, as evident in very old buildings where an original component continues to perform well (Silvestre, Silva and de Brito, 2012), but this is at variance with what obtains in practice as the life expectancy of building components is frequently much shorter due to several reasons. Silva et al. (2012) used multiple regression analysis to evaluate the service life of stone cladding and arrived at an average estimated service life of 77 years.

Silva et al. (2013) also applied multiple linear regression analysis to the prediction of the service life of external rendering by quantifying the qualitative variables that were based on the relationship between the overall degradation and the degradation associated with each specific characteristic of the façades, from which the estimated service life for each characteristic is obtained which led to an average estimated service life of 15 years. Wooldridge (2009) notes that since multiple regression allows the addition of more factors that contribute to explaining the dependent variable, it is expected that more efficient models are obtained.

The methodologies that allow for the evaluation of the durability of buildings and their service life prediction have been published by many international codes and regulations in countries like Japan (Principal Guide for Service Life Planning of Buildings), Great Britain (Guide to Durability of Buildings and Building Elements, Products and Components), Canada (Guidelines on Durability in Buildings). Also, standards relating to service life prediction have been published in countries that include: New Zealand (New Zealand Building Code 1992), which establishes a service life of 50 years for buildings and allows their components to have different service lives, depending on easy access, repair and anomaly detection; Australia (ABCB 2006); the United States, through the Partnership for Advancing Technology in Housing (PATH) that has funded a series of publications relating to the service life of buildings, and the American Society for Testing and Materials (ASTM); and Canada (Standard S478-95: Guideline on durability in buildings 2007) (Koymans, Abbott 2006)

Few types of research carried out in this area of study in the developing countries and especially in Nigeria are not on the service life of building components. For example, in a study carried out on service life by Adedeji (2002), the component service life was on coated brickwork mortar joint. Adeola, Jacob and Olumuyiwa (2011) carried out studies on the service life of a building attached with a solar chimney collector, the focus of the study was not on the building but the Chimney. Iweka and Adebayo (2011) researched the durability of building materials and only canvassed for the use of sustainable building materials that will meet service life requirements. Sule (2014) appraised the probable service life of abandoned building projects in Nigeria. Folorunso (2013) acknowledged the importance of service life but went further to set out parameters for building specifications. However, Folorunso (2014) found that buildings around the Atlantic coast will require repainting within 3 years of paint application while the frequency of repainting of painted exterior walls is required after every 4 years in other parts of the tropical zones that are not exposed to any contact with salt.

\subsection{Study Area}

The area for this study is Mandate 3 Housing Estate, Ilorin, Kwara State. It was one of the housing estates constructed by the state government, hence, had allowed for sufficient time for the external paint to have undergone the effect of climatic factors concerning the degradation of paint. Ilorin is located on Latitude $83^{\circ}$ North and 
Longitude $435^{\circ}$ East of the Greenwich Meridian. It is occupying an area of about $100 \mathrm{~km}^{2}$ (Kwara State Diary, 2005) situated in the Transition Zone between the deciduous woodland of the South and the Savanah of the North, thus giving it the status of "GateWay City" in Nigeria. Ilorin metropolis has a tropical wet-dry climate, days are very hot during the dry season from November to January while temperatures typically range from $33^{\circ} \mathrm{C}$ to $37^{\circ} \mathrm{C}$. The daily range of temperature during the rainy season is $8^{\circ} \mathrm{C}$. Rainfall condition in Ilorin exhibits greater variability both temporarily and spatially. The mean annual rainfall has been estimated to be $1318 \mathrm{~mm}$. It normally starts in April and ends in October; however, the rainfall intensity, frequency and amount vary from month to month. The dry season is characterized by cold and dry due to harmattan. Relative humidity in Ilorin in the wet season is between 75 to $80 \%$ while in the dry season it is about $65 \%$. The daytimes are sunny and the sun shines brightly for about 6.5 to 7.7 hours daily from November to May (National Bureau of Statistics, 2010).

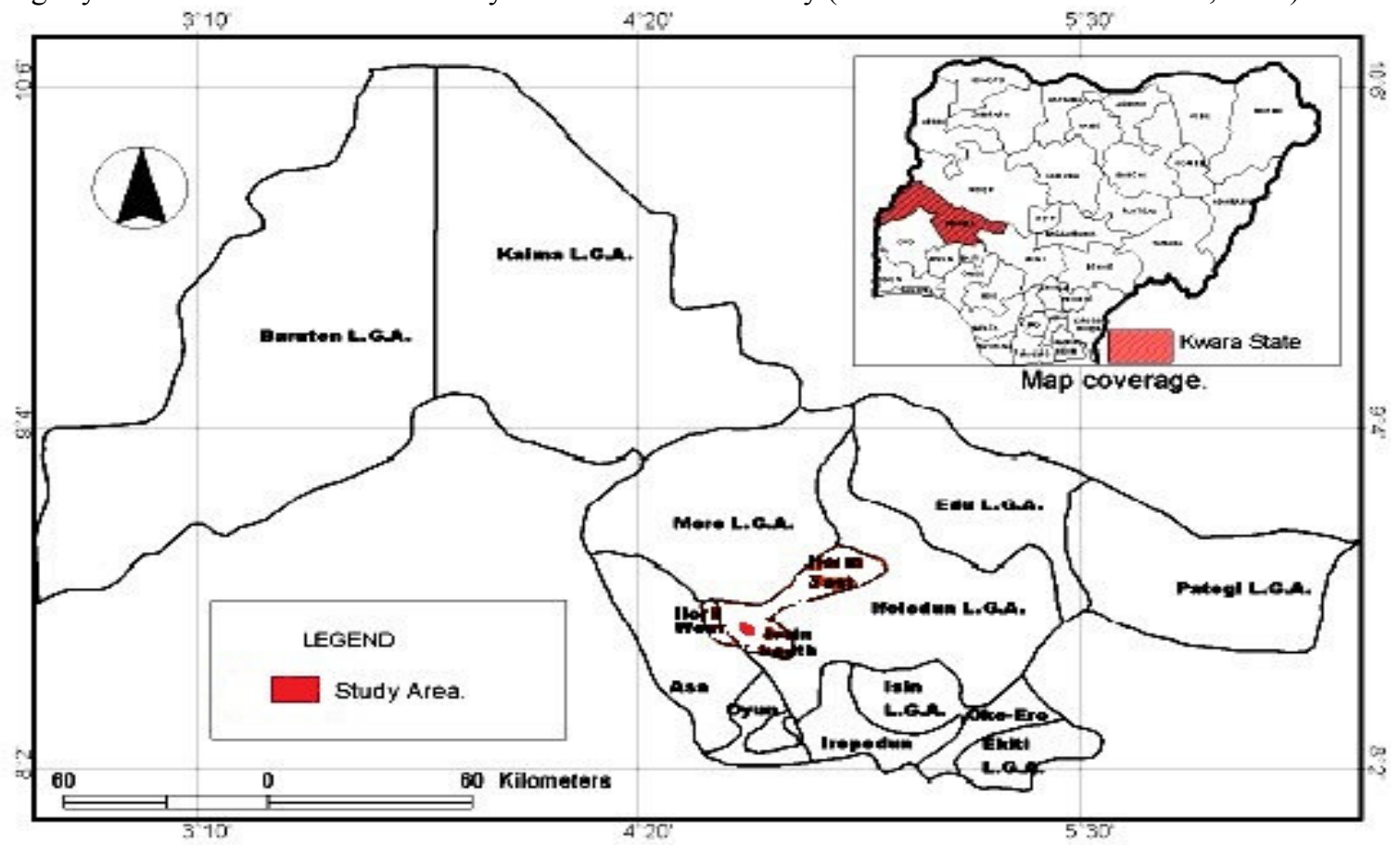

Figure 1: Map of Kwara State Showing Mandate 3 Estate

Source: Adebimpe, 2011.

\subsection{Material and Methods}

The research was carried out through a quantitative method that involved a field study and a visual survey. The state of the painted facade of 84 buildings was determined through in-service survey data generated through a structured questionnaire. The variables that determined the deterioration of the painted surfaces were evaluated and measured. The independent variables included in the model are the fifteen (15) predictors relating to the characteristics of the coatings under analysis, namely: age of the building, layout of the building, the distance of building from the road, the distance of building from the water body, distance of building to the forest/vegetation, level of exposure of building to wetness/dampness, building near any industrial facility, how many sides is a building surrounded by other residential blocks, the effect of wind action, the effect of rain action, description of the surface after the paint had been applied, type of paint used, description of the colour of paint after it had been applied, how was the paint applied, number of storeys, the extent of the defect(s) shown on the external surface of the building and the portion of the external surface where the defect is shown.

The dependent variable measures the extent or level of façade's degradation. Therefore, the level of degradation takes into account both the degraded area of the coating, affected by the various anomalies and the severity level of the anomalies. The anomalies are classified in terms of the condition through a four-scale measurement ranging from 1 as no visible defects, 2 as few signs of defects, 3 as general defects and 4 as severe defects. The variables that caused degradation of external paint finish were categorised into fifteen and made to be independent variables whereas the extent of the level of degradation of the external painted surface was made the dependent variable. Regression analysis was carried out and the stepwise method was used to select and build the regression model, including only the statistically significant predictors. In all, 16 variables were fed into SPSS version 16.0 . 
5.0 Findings and Discussions

Table 1: Frequency Distribution for the Building Characteristics of External Paint Finish

\begin{tabular}{|c|c|c|c|}
\hline Building Characteristics & Categories & Frequency & Percentage \\
\hline \multirow{4}{*}{ Age of Building } & Below 5years & 13 & 14.77 \\
\hline & $10-20$ years & 32 & 36.36 \\
\hline & Above 20years & 43 & 48.86 \\
\hline & Total & 88 & 100 \\
\hline \multirow[t]{5}{*}{ Façade Orientation } & North & 18 & 20.45 \\
\hline & South & 16 & 18.18 \\
\hline & East & 23 & 26.14 \\
\hline & West & 31 & 35.23 \\
\hline & Total & 88 & 100 \\
\hline \multirow[t]{3}{*}{ Layout of building } & $\begin{array}{l}\text { Regular (Rectangular, } \\
\text { Square) }\end{array}$ & 88 & 100 \\
\hline & $\begin{array}{l}\text { Irregular (Circular, } \\
\text { Triangular) }\end{array}$ & 0 & 0 \\
\hline & Total & 88 & 100 \\
\hline \multirow[t]{3}{*}{ The distance of Building to Road } & Less than 3 metres & 68 & 77.27 \\
\hline & 3 -6metres & 20 & 22.73 \\
\hline & Total & 88 & 100 \\
\hline \multirow[t]{4}{*}{ The distance of Building from Water Body } & Between 1 - 10 poles & $\mathbf{0}$ & $\mathbf{0}$ \\
\hline & Between $11-20$ poles & 88 & 88 \\
\hline & Above 20 poles & 0 & 0 \\
\hline & Total & 88 & 100 \\
\hline \multirow[t]{5}{*}{ The distance of Building to Forest } & Between $1-10$ poles & 0 & \\
\hline & Between $11-20$ poles & 0 & \\
\hline & Between $21-40$ poles & 0 & \\
\hline & Above 40 poles & 88 & 100 \\
\hline & Total & 88 & 100 \\
\hline \multirow[t]{5}{*}{ The distance of building from an industrial facility } & Between $1-10$ poles & 12 & 2.93 \\
\hline & Between $11-20$ poles & 0 & 0 \\
\hline & Between $21-40$ poles & 0 & 0 \\
\hline & Above 40 poles & 88 & 100 \\
\hline & Total & 88 & 100 \\
\hline \multirow[t]{5}{*}{$\begin{array}{l}\text { How Many Side is Building Surrounded by other } \\
\text { Buildings }\end{array}$} & On one side & 17 & 4.15 \\
\hline & On two sides & 53 & 60.23 \\
\hline & On three sides & 25 & 28.41 \\
\hline & On all sides & 10 & 11.36 \\
\hline & Total & 88 & 100 \\
\hline \multirow[t]{4}{*}{ Effect of Wind on Paint Finish } & Slight & 26 & 29.55 \\
\hline & Moderate & 32 & 36.36 \\
\hline & Severe & 30 & 34.09 \\
\hline & Total & 88 & 100 \\
\hline \multirow[t]{4}{*}{ Effect of Rain on Paint Finish } & Slight & 25 & 28.41 \\
\hline & Moderate & 32 & 36.36 \\
\hline & Severe & 31 & 35.23 \\
\hline & Total & 88 & 100 \\
\hline \multirow[t]{3}{*}{ Description of Surface of Paint after Painting } & Rough & 2 & 2.27 \\
\hline & Smooth & 86 & 97.73 \\
\hline & Total & 88 & 100 \\
\hline \multirow[t]{3}{*}{ Type of Paint Used } & Emulsion Paint & 84 & 95.45 \\
\hline & Gloss Paint & 4 & 4.55 \\
\hline & Total & 88 & 100 \\
\hline
\end{tabular}




\begin{tabular}{|c|c|c|c|}
\hline Building Characteristics & Categories & Frequency & Percentage \\
\hline \multirow[t]{4}{*}{ Description of the colour of paint used } & Bright & 63 & 71.59 \\
\hline & Cool & 25 & 28.41 \\
\hline & Dull & 0 & 0 \\
\hline & Total & 88 & 100 \\
\hline \multirow[t]{3}{*}{ How was the paint applied to the Surface } & $\begin{array}{l}\text { Applied directly to the } \\
\text { plastered wall }\end{array}$ & 20 & 22.73 \\
\hline & $\begin{array}{l}\text { Applied over the } \\
\text { existing paint }\end{array}$ & 68 & 77.27 \\
\hline & Total & 88 & 100 \\
\hline \multirow[t]{5}{*}{ Number of Storeys } & One level building & 44 & 50 \\
\hline & Two levels building & 32 & 36.36 \\
\hline & Three levels building & 12 & 13.63 \\
\hline & Four levels building & 0 & 0 \\
\hline & Total & 88 & 100 \\
\hline \multirow[t]{5}{*}{$\begin{array}{l}\text { The extent of the defect(S) shown on the external } \\
\text { surface of the building }\end{array}$} & No visible defects & 4 & 4.55 \\
\hline & Few signs of defects & 35 & 39.77 \\
\hline & General defects & 12 & 13.64 \\
\hline & Severe defects & 41 & 46.59 \\
\hline & Total & 88 & 100 \\
\hline \multirow[t]{4}{*}{$\begin{array}{l}\text { The portion of the external surface where the defect is } \\
\text { Shown }\end{array}$} & $\begin{array}{l}\text { Below the window } \\
\text { level }\end{array}$ & 51 & 57.95 \\
\hline & $\begin{array}{l}\text { Around the window } \\
\text { level }\end{array}$ & 10 & 11.36 \\
\hline & $\begin{array}{l}\text { Above the window } \\
\text { level }\end{array}$ & 27 & 30.68 \\
\hline & Total & 88 & 100 \\
\hline
\end{tabular}

The analysis of the frequency table obtained as shown in Table 1 above shows the following;

Age of building: 43 out of the 88 buildings (49\%) had been constructed over 20 years ago while $32(36 \%)$ had spent between 10 and 20 years. The implication is that 75 (84\%) of the buildings had experienced variations in the climatic conditions which may have allowed for repainting and maintenance of the building envelopes. This finding agrees with the position of Evelyn, Chew and Harikrishna (2005); Chai, De Brito, Gaspa and Silver (2014) that the age of buildings has a natural tendency on materials to undergo deterioration with time. The gradual loss of protective and other properties of the paint finish itself goes with age. Chai, De Brito, Gaspa and Silver (2014; 2015) buttress the fact that degradation factors of paint are explained by the age of buildings.

Façade Orientation: The analysis of the façade orientation in Table 1 indicates that out of 88 buildings across the residential estates, 31 (35.23\%) of the buildings are oriented towards the West, $23(26.14 \%)$ are oriented towards the East, $16(18.18 \%)$ towards the South and 18 (20.45\%) towards the North. Therefore, a total of 54 out of the 88 buildings had facades facing the East-West direction. The result is authenticated by the findings of Ogunsote and Adegbie (2010) who affirm that buildings whose longer side is laid along the East-West direction with the blank walls facing the East-West direction get protection from heat and scorching effects from direct solar radiation. This orientation also enhances the easy passage of South - West wind into the building. Facades facing away from direct radiation are comparatively colder and damper providing ideal conditions for algae and other microbial growth. Chew and Tan (2003) also identify that façades directly exposed to sunlight undergo greater physical weathering, leading to chalking of paint. Gaspar (2009) reports that the most aggressive directions are usually north because greater humidity is combined with fewer hours of sunshine, and then the west because of strong solar exposure leading to temperatures that may affect the walls. Generally, there is a higher incidence of cracking, detachment, colour/brightness changes, and chalking on façades facing south and west, and of biological stains on façades facing north. The outcome of the findings of Chai, de Brito, Gaspar, and Silva (2014) support the findings of this study by submitting that the degradation potential of paint coatings increases from North, East and West to South.

The layout of Buildings: The analysis of the shape of the plan view as shown in Table 1 reveals that $100 \%$ of the buildings in the estates are of regular shape. Evelyn, Chew and Hariskishna (2005) opine that regularity or irregularity of the shape of plan view affects the ease of access to the affected areas, hence, identification of defects through visual observation or other means. It also influences the timing of maintenance, repair and service life. Teo and Hariskhina (2006) further argue that a building with regular geometry/layout would have a lower defect index value than a building with an irregular layout, due to the difficulties of detecting and sealing the crack 
mapping patterns, thereby reducing the incidence of further cracking.

The distance of Buildings to Road: The frequency result on the distance of the buildings to the road in Table 1 reveals that 68 (77.27\%) of the buildings out of 88 sampled were less than 3 metres to the road, while the remaining $22.73 \%$ were between $3 \mathrm{~m}$ and above to the main road. Distance to the road plays a major role in the degradation of the external paint finish. According to Teo and Harikishna (2006), the proximity of the building to the main road leads to a higher deposition of impurities on the finished surface and adds to the crazing.

The distance of Building from Water Body: According to the classification of this study, the distance between the stratification of poles (1Pole-10Poles) is $0.5 \mathrm{~km}$. Therefore 20 poles translate to $1 \mathrm{~km}$ and 40 poles to $2 \mathrm{~km}$. Exposure to humidity signifies favourable when the distance from the building to the water body, foliage and vegetation is more than $1 \mathrm{~km}$ and unfavourable when the distance is less than $1 \mathrm{~km}$. The analysis of the distance to the water body in Table 1 reveals that out of 88 buildings across the estate, $88(100 \%)$ is at a distance between 11 poles and above. The implication is that $100 \%$ of the buildings are located above $1 \mathrm{~km}$ to the buildings which made them susceptible to the effect of humidity. The findings agree with Evenly, Chew and Harikrishna (2005); Teo and Harikrishna (2006); Shohet and Paciuk (2006) that seashore environment and ultraviolet radiation (associated with façade orientation) are typical mechanisms of failure that lead to degradation of exterior claddings

The distance of Building to Forest: The frequency result of distance of building to the forest in the table shows that $88(100 \%)$ of the buildings were located at a distance of $2 \mathrm{~km}$ and above to the forest. This implies that the majority of the buildings were favourable in terms of the effect of humidity. The buildings in the zone are not located near the forest and are therefore not vulnerable to the effect of humidity and fluctuations in moisture levels and condensation, thereby causing possible water impregnation and damage in the form of crack patterns against the postulations of Gasper and de Brito (2008).

The distance of Building from Industrial Facility: The analysis of the distance of buildings from an industrial facility in the table reveals that $88(100 \%)$ out of the 88 buildings were located above $2 \mathrm{~km}$ to the industrial site. This has settled the concern of Evelyn, Chew and Harikrishna (2005) who posit that acid and location of building from industrial source pose a greater risk of gaseous and particulate exhaust emissions that can have a serious effect on paint systems, by corroding the surface.

Surrounding Buildings: The effect of adjacent and surrounding buildings was sought from the respondents and the analysis of the frequency result reveals that $88(100 \%)$ of the buildings were surrounded on either one, two, three or four sides. Proximity to other residential blocks also has a decreasing effect on the defect index value since the surrounding environment ensures that a good proportion of the overall facade area is not exposed to direct solar radiation and the ultraviolet components of sunlight, which tend to break down the paint film and the colouring pigments (chai, 2011). The presence of adjacent buildings provides a sheltering effect and may result in a slower drying period for façade after it has been wet, leaving it damp for longer periods and therefore promoting biological staining (Evelyn, Chew and Harikrishna, 2005; Silva, de Brito, Gaspar 2011).

Effect of Wind and Rain on Paint Finish: The analysis of the effect of wind and rain in the frequency results in Table 33 indicates that all the 88 buildings manifested a varying degree of defects ranging from slight $26(29.55 \%)$, moderate $32(36.36 \%)$ and severe $30(34.09 \%)$. The effect of rain on the table equally reveals that $57(64.77 \%)$ were moderate and $31(35.23 \%)$ were severe. Facade degradation occurs due to the combined effects of rain, wind, sunlight, biological and atmospheric pollutants. This process is generally set in motion by rainwater and its flow down the facade (runoff) that will result either in washing or deposition of dirt over its surface (Chew and Tan, 2003). The combined action of wind and rain will not only change the direction of the fall of raindrops so that they impinge on the surfaces of the wall but also alter the pattern of runoff flow on the facade (Choi, 1994, 1999; Rydock, 2007). Water brings along dirt and pollutant particles that are retained on or adhere to the facade material, parapets, or ledges (Chew and Tan, 2003). Wind and rain are two of the main physical agents in the degradation of external finish (Camuffo, 1995; Barberousse, Ruot, Yéprémian, and Boulon 2007). Coatings subjected to a severe wind-rain action degrade fastest followed by those exposed to moderate action, and then the shorter buildings, in dense urban areas subjected to a slight action (Silva, de Brito and Gaspar, 2011).

Description of Surface of Paint after Painting: table 1 shows the analysis of the surface after repainting. 2 $(2.27 \%)$ of the buildings showed a rough surface while $86(97.73 \%)$ exhibited a smooth surface. Dias, Silva, Chai, $\mathrm{C}$, Gaspar, de Brito (2014) strengthen the perception of the technical community that degradation is a function of the finishing of the painted surfaces in which the performance and durability of rougher paints are greater. The greater the roughness and porosity of the substrate, the more likely the occurrence of paint defects due to the higher tendency to trap dirt and water (Teo and Harikshna, 2005)

Type of Paint Used: The analysis of the type of paint used as shown in the table indicates that $84(95.45 \%)$ out of 88 buildings made use of emulsion paint while $4(4.55 \%)$ used gloss paint as an external finish.

Description of Colour of Paint after Use: The analysis of the description of the colour of paint reveals that 63 $(71.59 \%)$ out of the 88 buildings used the bright colour, $25(28.41 \%)$ used cool colour. This finding corroborates the assertion of Chai (2011) that dull and sober colour tones obtained from inorganic pigments are more resistant to sunlight and have lower fading rates than brighter and more exotic colour tones obtained from organic pigments. 
Chalking is generally more prevalent in bright and exotic coloured paint films compared to dark-coloured paint films depending on the type of paint used.

Application of Paint to the Surface: On the application of paint to the surface, the analysis indicates that 68 (77.27\%) of the buildings applied the paint over the existing one, while $20(22.73 \%)$ applied directly to the plastered wall. When the paint is applied over a previous coat, there is a greater probability of product incompatibility and worse adhesion conditions (Chai, de Brito, Gaspar and Silva, 2014).

Number of Storeys: All the 88 (100\%) of the buildings fell within one and three levels. Choi (1994) maintains that tall buildings are at greater risk of deterioration due to their direct exposure to impacting rain and ultraviolet radiation. Wind speed varies with height due to the level of openness as well as the instability of air at higher levels. The costs of maintenance and repair of defects to the façade are more for higher storeys due to additional costs in the form of scaffolding, and safety during work in higher storeys (Evelyn, Chew and Harikrishna (2005). The extent of Defect(s) Shown on the External Surface of Building: The analysis of the extent of defects reveals that $84(95.45 \%)$ manifested a varying degree of defects ranging from few signs of defects to severe defects, while $4(4.55 \%)$ showed no visible signs of defects. It implies that most of the buildings exhibit the characteristics of degradation of the painted surface irrespective of where the defects manifest

The portion of External Surface Where Defect is Shown: The frequency result indicates that $51(57.95 \%)$ out of 88 buildings showed the defects below the window level. $10(11.36 \%)$ displayed the defects around the window level, while 27 (30.68\%) exhibited the defects above the window level.

Table 2: Summary of Regression Analysis Showing the Effects of Building Characteristics on External Paint Degradation

\begin{tabular}{|c|c|c|c|c|}
\hline Variables & Coef. & $\mathrm{Z}$ & $\rho$ & $\rho$ \\
\hline Age & .095 & 0.29 & 0.007 & \\
\hline Façade Orientation & .190 & 0.83 & 0.040 & \\
\hline Building Layout & -0.223 & -0.45 & 0.005 & \\
\hline Distance to road & -.705 & -0.92 & 0.000 & \\
\hline Distance to river & -.273 & -0.71 & 0.480 & \\
\hline Distance to vegetation & -0.316 & -0.97 & 0.176 & \\
\hline Distance of industry & -.276 & -0.89 & 0.406 & 0.000 \\
\hline Surrounded by buildings & -. 160 & -0.36 & 0.071 & \\
\hline Wind effect & .758 & 0.84 & 0.009 & \\
\hline Rain effect & .875 & 0.98 & 0.332 & \\
\hline Surface after repaint & .724 & 0.02 & 0.988 & \\
\hline Type of paint used & .628 & 0.01 & 0.008 & \\
\hline Colour of paint & .490 & 0.59 & 0.005 & \\
\hline Paint application & -.220 & -0.28 & 0.778 & \\
\hline Number of storeys & -0.400 & -0.52 & 0.601 & \\
\hline Potion of defect & -.190 & -1.02 & 0.003 & \\
\hline
\end{tabular}

The variables that caused degradation of external paint finish were characterised based on the past researches that had been undertaken on service life of painted surfaces. Regression analysis was carried out to estimate the factors responsible for the defects of external paint finish. Table 2 shows the regression coefficients of the building characteristics responsible for the extent of defects of external paint finish. The coefficients are based on dependent and independent variables, which depends on the main and interaction effects. The table reveals that all the selected building characteristics of age of building $(\operatorname{coef}=.095, \rho=\mathbf{0 . 0 0 7}<\mathbf{0 . 0 0 5})$, façade orientation (coef $=.190, \rho=$ $\mathbf{0 . 0 4 0}<\mathbf{0 . 0 0 5}$ ), building layout (coef $=0.223, \rho=\mathbf{0 . 0 0 5}<\mathbf{0 . 0 0 5})$, distance to road (coef $=-.705, \rho=\mathbf{0 . 0 0 0}<$ 0.005), distance to river (coef $=-.273, \rho=0.480>0.005)$, distance to vegetation (coef $=-0.316, \rho=0.176>$ 0.005 ), distance to industry (coef $=-.276, \rho=0.406>0.005)$, surrounded by other buildings (coef $=-.160, \rho$ $=0.071>0.05)$, wind effect ( $\operatorname{coef}=.758, \rho=\mathbf{0 . 0 0 9}<\mathbf{0 . 0 5})$, rain effect $(\operatorname{coef}=.875, \rho=0.032>0.05)$, surface after repaint $(\operatorname{coef}=.724, \rho=0.988>0.05)$, type of paint used $(\operatorname{coef}=.628, \rho=\mathbf{0 . 0 0 8}<\mathbf{0 . 0 5})$, colour of paint used (coef $=.490, \rho=\mathbf{0 . 0 0 5}<\mathbf{0 . 0 5}$ ), paint application (coef $=-.220, \rho=0.778>0.05)$, number of storeys (coef $=-0.400, \rho=0.601>0.05)$, portion of defect (coef $=-.190, \rho=\mathbf{0 . 0 0 3}<\mathbf{0 . 0 5}$ ) had significant and joint prediction on the extent of defect of external paint finish. However, Age, Façade Orientation, building layout, distance to road, wind effect, type of paint used, colour of paint used and portion of defect had significant and independent prediction on the external paint finish $(\rho=<0.05)$ 
Table 3: Summary of regression analysis showing the effects of defect factors on external paint degradation

\begin{tabular}{lrrrrr}
\hline Variables & Coef. & \multicolumn{1}{c}{ Z } & $\rho$ & Pseudo $\mathbf{R}^{\mathbf{2}}$ & $\rho$ \\
\hline Age & $\mathbf{. 0 9 5}$ & $\mathbf{0 . 2 9}$ & $\mathbf{0 . 0 0 7}$ & \\
Building Layout & $\mathbf{- 0 . 2 2 3}$ & $\mathbf{- 0 . 4 5}$ & $\mathbf{0 . 0 0 5}$ & \\
Distance to road & -.705 & -0.92 & 0.000 & & $\mathbf{0 . 0 0 0 0}$ \\
Wind effect & .758 & $\mathbf{0 . 8 4}$ & $\mathbf{0 . 0 0 9}$ & $\mathbf{. 5 2 8 3}$ & \\
Type of paint used & $\mathbf{. 6 2 8}$ & $\mathbf{0 . 0 1}$ & $\mathbf{0 . 0 0 8}$ & \\
Colour of paint & $\mathbf{4 9 0}$ & $\mathbf{0 . 5 9}$ & $\mathbf{0 . 0 0 5}$ & \\
Potion of defect & $\mathbf{- . 1 9 0}$ & $\mathbf{- 1 . 0 2}$ & $\mathbf{0 . 0 0 3}$ & \\
\hline
\end{tabular}

The result $\rho=0.0000<.05$, Pseudo $\mathrm{R}^{2}=.5328$ in table 3 implied that $53 \%$ of the variance in the degradation of external paint finish is accounted for by the selected independent variables of the age of the building, façade orientation, building layout, distance to road, wind effect, type of paint used, colour of paint, and portion of defect.

The explanatory variables were defined using the stepwise method in which case, all the variables that were not significant ( $\rho=>0.05$ ) were excluded. Linear regression allows identifying the characteristics that influence the durability of paintings and also establishes a hierarchical distinction between the different characteristics, evaluating which variables are more relevant to the degradation of painted surfaces. The model presents a very strong correlation between variables, deemed appropriate to model the durability of painted surfaces.

Eight independent explanatory variables analysed using this model were façade orientation, distance to the river, the effect of wind, type of paint used, colour of paint and portion of external surface where the defect is visible as shown in Table 3 . The result which is statistically significant at 0.05 (95\%) confidence interval indicates that as the ratings of the building characteristics increase, the extent of defects of external paint finish also increases. Table 4: Residuals Statistics of the Linear Regression for the Predicted Service Life at Mandate 3 Housing Estate, Ilorin. Kwara State (Transitional Zone)

\begin{tabular}{lccccc}
\hline & Minimum & Maximum & Mean & Std. Dev & N \\
\hline Predicted Value & $\mathbf{. 8 9 0}$ & $\mathbf{2 . 5 8 0}$ & $\mathbf{1 . 6 6 0}$ & .308 & 88 \\
Residual & -1.331 & 1.390 & .000 & .618 & 88 \\
Standard Predicted Value & -2.030 & 2.414 & .000 & 1.000 & 88 \\
Standard Residual & -2.116 & 2.210 & .000 & .983 & 88
\end{tabular}

Table 5: Summary of the Statistical Indicators for the Reference Service Life Estimated Using the Proposed Linear Regression Model in Mandate 3 Housing Estate, Ilorin. Kwara State (Transitional Zone)

\begin{tabular}{ll}
\hline Statistical Indicator & Values (Years) \\
\hline Average of the reference life & 1.7 \\
Maximum reference service life & 2.6 \\
Minimum reference service life & 1.0 \\
Range of reference service lives & 1.6 \\
The standard deviation of the reference service life & .308 \\
The variance of the reference service life & .6
\end{tabular}

Table 4 shows the residual statistics of the linear regression for the predicted service life in Mandate 3 Estate in Ilorin, Kwara State while table 5 provides the summary of the statistical indicators for the reference service life estimated, which includes a maximum value, a minimum value, a range and a standard deviation of the reference service life for the Transitional Design Climatic Zone of Nigeria. The estimated reference service life in the transitional climatic design zone of Nigeria is ( 2 years) given by this model. The minimum reference service life is 1 year, while the maximum service reference life is 3 years.

\subsection{Maintenance Guide for External Paints Finish}

Based on the estimated reference service life of 2 years, the minimum reference service life of 1 year and maximum service reference life of 3 years in the transitional climatic design zone of Nigeria as given by this model, an analysis was then performed that suggested maintenance strategies at an interval of 3 years and terminates at a period of 15 years. The repair and maintenance costs presented in table 5 for 3 years interval was calculated with the assistance of a Quantity Surveyor under the Nigerian reality.

The cost differential rate or consumer price index (CPI) in Nigeria is calculated monthly by the National Bureau of statistics, based on the consumption habits of Nigerian households based on monthly expenditure on food, housing, education, health and transport. In this study, a discounted rate of $12 \%$ is adopted for the cost differential rate (an average computed by the CBN between 1980 and 2015 is $11.38 \%$ ). The difference between the CPI of one month in a preceding year over the CPI of the same month in the current year is known as the inflation rate. Based on this, the average inflation rate computed from 2001 to 2005 is $0.27,2006$ to 2010 is 0.52 
and 2011 to 2015 is 1.03 from the information supplied by Nigeria Historical Inflation Rate (2006-2017). This implies that the inflation rate doubles every 5 years. Therefore, for this study, the inflation rate between 2011 and 2015 was used as the basis to project the inflation rate for the next 20 years. However, for further applications of the method, it is emphasized that economic parameters fluctuate monthly under the world economic cycles.

Table 5 shows that the cost of maintenance in 3 years after the completion of the building is $896.36 / \mathrm{m}^{2}$ using the inflation index. The predicted value of $896.36 / \mathrm{m}^{2}$ was discounted at an interest rate of $12 \%$ and the present value is $638.12 / \mathrm{m}^{2}$. This implies that for maintenance purpose in 3 years, the owner of the building needs to save the sum of $638.12 \mathrm{x}$ ' $\mathrm{Z}$ ' $\mathrm{m}^{2}$ where ' $\mathrm{Z}$ ' is the area of the external wall to be painted. This is also applicable for 6, 9 and 12 years projections. The present-value cost of the maintenance plan over 12 years is thus determined as a maintenance guide every 3 years following the results of this study, in terms of the paint estimated servicelife.

Table 6: Cost of the Maintenance Works for Transitional Zone (Kwara State)

\begin{tabular}{|c|c|c|c|c|c|}
\hline $\begin{array}{l}\text { Periodicity } \\
\text { (Years) }\end{array}$ & $\begin{array}{l}\text { Maintenance } \\
\text { Actions }\end{array}$ & $\begin{array}{l}\text { Cost in year } 0 \\
\left(\mathrm{~A} / \mathrm{m}^{2}\right)\end{array}$ & $\begin{array}{l}\text { Current cost }(\mathrm{A} / \\
\left.\mathrm{m}^{2}\right)\end{array}$ & $\begin{array}{l}\text { Present } \\
\left(\$ / \mathbf{m}^{2}\right)\end{array}$ & Value \\
\hline \multirow[t]{4}{*}{3} & Material (Paint) & 512.62 & & & \\
\hline & Scaffolding & 44.60 & 896.36 & 638.12 & \\
\hline & Labour & 66.90 & & & \\
\hline & Profit and Overhead & 89.20 & & & \\
\hline \multirow[t]{4}{*}{6} & Material (Paint) & 512.62 & & & \\
\hline & Scaffolding & 44.60 & 1790.28 & 906.96 & \\
\hline & Labour & 66.70 & & & \\
\hline & Profit and Overhead & 89.20 & & & \\
\hline \multirow[t]{4}{*}{9} & Material (Paint) & 512.62 & & & \\
\hline & Scaffolding & 44.60 & 3585.43 & 1292.91 & \\
\hline & Labour & 66.70 & & & \\
\hline & Profit and Overhead & 89.20 & & & \\
\hline \multirow[t]{5}{*}{12} & Cleaning and Repair & 33.45 & & & \\
\hline & Material (Paint) & 512.62 & & & \\
\hline & Scaffolding & 44.60 & 7507.76 & 1927.24 & \\
\hline & Labour & 66.70 & & & \\
\hline & Profit and Overhead & 89.20 & & & \\
\hline
\end{tabular}

\subsection{Conclusion}

A degradation model was applied to characterize the degradation of façade paint finish over time based on the findings of various researchers. The result of this study which puts the life span of external paint finish in the transitional zone in Nigeria at 2 years disagrees with the findings of Folorunso (2014) that buildings around the Atlantic coast will require repainting within 3 years of paint application while the frequency of repainting of painted exterior walls is required after every 4 years in other parts of the tropical zones that are not exposed to any contact with salt. It also disagrees with Onwuka, (1989); Roy, Thye, and Northwood (1996); ASTM (2005) and Bliss (2006) who identified paint used in tropical areas to have a life span of between 5-7years. However, the result supports the findings of Aluko (2018) that climatic location will significantly affect external paint degradation. The residual service life of building elements is an important piece of information for refurbishment decisions that should be economical as well as sustainable. The service life generated in this study can be used to prepare budgets, determine the optimal timing, magnitude and cost of maintenance/repair work at a different time during the lifetime of the external paint finish.

\section{References}

Abbott, G. R.; Mc Duling, J. J.; Parsons, S.; Schoeman, J. C. (2007). Building condition assessment: a performance evaluation tool towards sustainable asset management, in CIB World Congress "Construction for Development", 14-18 May 2007, Cape Town, South Africa, 649-662.

Raheem Usman Adebimpe, 2011. Climate Change Related Disasters and Vulnerability: An Appraisal of the Nigerian Policy Environment. Environmental Research Journal, 5: 97-103

Adedeji, A. A. (2002). Estimation of the service life of coated brickwork mortar joint, cement and concrete research, Elsevier Science Publishing Company, Inc.

Adeola, A., Jacob. O. A., \& Olumuyiwa A. L. (2011). Service Life Assessment for A Building Attached with A 
Solar Chimney-Collector, Epistemics in Science, Engineering and Technology, 1 (3), 138-147.

Aluko, O.O. (2018). Degradation of external paint finishes in different climatic design zones of Nigeria. PhD Thesis, School of Postgraduate Studies, Federal University of Technology, Akure.

Aluko, O.O., Ogunsote, O.O., \& Adedeji, Y.M.D., 2018. Evaluation of the service life of external paint finishes in Public Residential Buildings in the coastal climatic zone of Nigeria. Environmental Technology and Science Journal, (9) 2, 26-34.

ASTM (2005). International Building Inspection Guidelines, available at http://www.barrie101.com/lifs_expectancy, accessed 19th September 2018.

Australian Building Codes Board (2006). Durability in buildings. Guideline document. Australia, Canberra.

Barberousse H., Ruot B, Yéprémian C., \& Boulon G. (2007). An assessment of façade coatings against colonisation by aerial algae and cyanobacteria. Build Environ 42 (7), 2555-2561.

Bliss, S. (2006). Best Practices Guide to Residential Construction: Materials, Finishes and Details. John Willey $\&$ Sons, New York.

Camuffo, D. (1995). Physical weathering of stones. Sci Environ;167 (1-3), 1-14.

Chai, C. (2011). Service Life Prediction of Painted Surfaces in External Walls. Master Dissertation in Civil Engineering, Instituto Superior Técnico, Technical University of Lisbon, Portugal.

Chai, C., de Brito, J., Gaspar, P. L., \& Silva, A. (2014). Predicting the service life of exterior wall painting: Technoeconomic analysis of alternative maintenance strategies, Journal of Construction Engineering and Management 140 (3). 04013057

Chai, C., de Brito, J., Gaspar, P. L., \& Silva, A. (2015). Statistical modelling of the service life prediction of painted surfaces. International Journal of Strategic Property Management. 19 (2), 173-185.

Chew, M., \& Tan, P. (2003). Staining of facades. World Scientific, Singapore.

Choi E. C. (1994). Parameters affecting the intensity of wind-driven-rain on the front face of a building. Wind Engineering and Industrial Aeronautics, 53 (1-2), 1-17.

Choi E. C. (1999). Wind-driven rain on building facades and the driving rain index. Wind Engineering and Industrial Aeronautics, 79 (1-2),105-22.

Daniotti, B. \& Paolini, R. (2005). Durability design of external thermal insulation composite systems with rendering, in the 10th DBMC International Conference on Durability of Building Materials and Components, 17-20 April, Lyon, France, 269-276.

de la Fuente, D., Chico, B., \& Morcillo, M. (2006). The effects of soluble salts at the metal/paint interface: Advances in knowledge. Portugaliae Electrochemica Acta, 24: 191-206.

El-Haram, M.A. and Horner, M.W. (2002). "Factors affecting housing maintenance cost", Journal of Quality in Maintenance Engineering, 8 (2), 115-23.

Evelyn, T., Chew M., \& Harikrishna, N. (2005). An Assessment of Factors Affecting the Service Life of External Paint Finish on Plastered Facades. International Conference on Durability of Building Materials and Components. LYON, France.

Folorunso, C. O. \& Mohd, H. A. (2013). Parameters for Building Materials Specifications in Lagos, Nigeria, SAGE Open, 2013, DOI: 10.1177/2158244013497724

Folorunso C.O. (2014). Building Exterior Paint Performance in Tropical Salty Environment of Lagos. PhD Thesis, Faculty of Built Environment, University of Technology, Malaysia.

Gaspar, Pedro., \& Brito Jorge de. (2008). Quantifying environment effects on cement rendered facades: A comparison between different degradation indicators. Building and Environment;43 (11), 818-828.

Gaspar, P. (2009). Service Life of Constructions. Development of a Methodology to Estimate the Durability of Construction Elements, Application to Renders in Current Buildings (in Portuguese). PhD Thesis in engineering sciences at Instituto Superior Técnico, Lisbon, Portugal.

ISO 15686-1. (2000). Building and Constructed Assets: Service Life Planning - part1: General principles. Geneva: International Standard Organization.

Iweka, Anthony C.O., \& Adebayo Anthony K. (2011). Improving housing durability in deprived settlements of Lagos megacity through Ingenuous use of sustainable indigenous materials. International Journal of Sustainable Construction Engineering \& Technology $99-111$.

José Dinis Silvestre, Ana Silva, Jorge de Brito (2012). Uncertainty Modelling of Service Life and Environmental Performance to Reduce Risk in Building Design Decisions Journal of Civil Engineering and Management 21(3), 308-322

King, G. (1986). How not to lie with statistics: avoiding common mistakes in quantitative political science, American Journal of Political Science 30, 666-687.

Kus, H.; Nygren, K.; \& Norberg, P. (2004). In-use performance assessment of rendered autoclaved concrete walls by long-term moisture monitoring, Building and Environment 39 (6), 677-687.

Kwara State of Nigeria. Kwara State diary. (2005). Government Press.

Lacasse, M. A.; Sjöström, C. (2004). Recent advances in methods for service life prediction of buildings materials 
and components - an overview, in CIB World Building Congress, 2-7 May, Toronto, Ontario, Canada, pp. $1-10$.

Lee, R., \& Wordsworth, P. (2001). Building Maintenance Management. Fourth Edition. Blackwell Science. Cambridge MA. 340.

Morcillo, M. (1999). Soluble salts: Their effect on premature degradation of anticorrosive paints. Progress in Organic Coatings, 36, 137-147.

Moser, K. (2004). Engineering design methods for service life prediction, in CIB W80 / RILEM 175 - Service Life Methodologies; Prediction of the service life of Buildings and Components, Task Group: Performancebased methods of service life prediction. Trondheim, Norway, 52-95

National Bureau of Statistics. (2010). Commercial Agriculture Development Project (CADP), NBS/CADP Baseline Survey Report.

New Zealand Building Code (1992). New Zealand: Ministry of Business, Innovation and Employment, 88.

Norvaišiene, R., Miniotaite, R., \& Stankevicius V. (2003). Climatic and air pollution effects on building facades. Material Science). 9 (1)

Ogunsote O., Prucnal Ogunsote., \& Adegbie, M. O. (2010). Optimizing passive cooling system in residential buildings: A case study of Akure, Nigeria. Proceeding of the 1st international SET conference, Federal University of Technology, Akure, Oct 25-27. 215-217.

Olanrewaju, R.M. (2009). Climate and the growth cycle of yam plant in the guinea savannah ecological zone of Kwara State, Nigeria. Journal of Meteorological and Climate Science, 7, 43-48.

Onwuka, E.E. (1989). Maintenance in Building and Construction Works. Journal of Nigeria Institute of Quantity Surveyor, 3 (1), 3-8.

Roy, S.K., Thye, L.B., \& Northwood, D.O., 1996. The evaluation of paint performance for exterior applications in Singapore's tropical environment. Building and Environment, 31 (5), 477-86.

Rydock J., 2007. Validation of a present weather observation method for driving rain mapping. Building and Environment, 42 (2), 566-571.

Satapathy, S.C., Murthy, J.V.R., Reddy, P.V.G.D.P., Misra, B.B., Dash, P.K., Panda, G. (2009). Particle swarm optimized multiple linear regression linear model for data classification, Applied Soft Computing 9 (2), 470 476.

Silva. A., de Brito J., \& Gaspar, P. (2011). Service life prediction model applied to natural stone wall claddings, (directly adhered to the substrate). Construction and Building Materials 25 3674-3684.

Silva, A., Dias, J. L., Gaspar, P. L., de Brito, J. (2011). Service life prediction models for exterior stone cladding, Building Research \& Information 39 (6), 637-653.

Silva, A., de Brito, J., Gaspar, P. (2012). Application of the factor method to maintenance decision support for stone cladding, Automation in Construction 22, 165-174.

Silva, A., Dias, J.L., Gaspar, P., de Brito, J. (2013). Statistical model applied to service life prediction of rendered façades, Automation in Construction 30: 151-160.

Singhaputtangkul, N., Low, S.P., \& Teo, A.L. (2011). Integrating sustainability and buildability requirements in building envelope. Facilities, 29 (5\&6), 255-267

Sohet, I. M., \& Paciuk, M. (2006). Service life prediction of exterior cladding components under failure conditions, Construction Management Economics. 24 (2),131-48.

Sule, S. (2014). Probabilistic service life appraisal of abandoned building projects in Nigeria. Scholars Journal of Engineering and Technology, 2 (2A), 105-107.

S478-95 Guideline on durability in buildings (2007). Canada: CSA Group,112.

Teo, E. A. L., \& Harikrishna, N. (2005). Maintenance of plastered and painted facades for Singapore public housing: A predictive life cycle cost-based approach. Architectural Science Review. 48 (1), 47-54.

Teo, E. A. L., \& Harikrishna, N. (2006). A quantitative model for efficient maintenance of plastered and painted facades, Construction Management and Economics. 24, 1283-1293.

Wooldridge, J.M. (2009). Introductory econometrics: a modern approach. South-Western College Publishing, Cengage Learning. 912. USA.

Yang, J., Wang, X., \& JU, C. (2012). Discussion and analysis on the fungus, humidity and salt fog environmental test. Advanced Materials Research, 560-561, 469-473. 